\title{
Wear Resistance and Indentation Behavior of Equiatomic Superelastic TiNi and 60NiTi
}

\author{
Rabin Neupane, Zoheir Farhat \\ Department of Process Engineering and Applied Science, Materials Engineering Program, Dalhousie University, \\ Halifax, Canada \\ Email: Rabin.Neupane@dal.ca
}

Received 18 April 2015; accepted 28 July 2015; published 31 July 2015

Copyright (C) 2015 by authors and Scientific Research Publishing Inc.

This work is licensed under the Creative Commons Attribution-NonCommercial International License (CC BY-NC).

http://creativecommons.org/licenses/by-nc/4.0/

(c) () (9) Open Access

\begin{abstract}
Indentation and reciprocating wear tests are carried out to study dent and wear resistance of superelastic Ti-Ni alloys. The effect of loading rate on the superelastic behavior of TiNi under indentation loading is investigated and compared to a new generation of shape memory alloys, i.e., $60 \mathrm{NiTi}$. Only limited amount of work has been done to investigate the dependency of superelasticity on loading rate of TiNi under localized compressive loads, but much work is directed towards understanding the effect of strain rate on tensile properties. Understanding the superelastic behavior helps to employ superelastic alloys in applications where high impact loading is expected as in bearings and gears. In the present study, it is found that dent resistance of Ti-Ni alloy is not significantly affected by loading rate (within the employed loading conditions). It has also been found that new-generation 60NiTi alloy exhibits superior wear and dent resistance, as well as higher hardness compared to equiatomic TiNi.
\end{abstract}

\section{Keywords}

TiNi, 60NiTi, Superelasticity, Dent Resistance, Wear Resistance

\section{Introduction}

TiNi shape memory alloys are widely known for shape memory and superelastic effects, which occur due to reversible martensitic transformation that can be induced either thermally or mechanically [1] [2]. TiNi exhibits superelastic effect through stress-induced martensitic transformation (i.e., phase transformation) between parent austenite phase and martensite phase, leading to high recoverable strain during deformation. During loading, the parent austenite phase transforms to twinned martensite followed by detwinning of martensite, i.e., reorientation 
of martensitic variants, accompanied by large strain. The reverse transformation from martensite to austenite occurs upon unloading, accompanied by large recoverable strain [2].

$\mathrm{TiNi}$ is widely used in a variety of applications in automotive, aerospace, and biomedical industries due to their high corrosion resistance, good fatigue properties, high mechanical damping and good ductility [2]-[5]. Recent studies have shown that superelastic TiNi has superior wear and dent resistance compared to other conventional materials [3] [6] [7]. There are currently extensive efforts to develop bearings and gears using superelastic TiNi alloys [8] [9]. Conventional bearing materials, such as AISI 52100, AISI M-50, AISI 440C steels and carbon steels, are susceptible to denting and wear during high loading [10]. It is expected that new high precision bearings made from superelastic TiNi alloy may provide superior wear and dent resistance during high impact loading conditions. In the case of conventional materials, wear and dent resistance depend on their mechanical properties such as strength, hardness, toughness, ductility, work hardening and crystallography texture [3]-[5]. However, for superelastic TiNi, in addition to mechanical properties, stress-induced martensitic transformation plays a major role in the observed wear and dent behavior [3] [10] [11].

The micromechanical and tribological characteristics of superelastic TiNi are studied by Farhat et al. [11]. They performed wear tests on superelastic TiNi and compared to Ti, Ni and AISI 304 steel using pin-on-disc configuration. Amongst all the materials tested, TiNi alloy showed about 30 and 10 times higher wear resistance than pure $\mathrm{Ti}$ and $\mathrm{Ni}$, respectively. Li et al. [12] studied the sliding wear behavior of Ti-50.3 at \%Ni alloy and $2 \mathrm{Cr} 13$ steel. They found that TiNi alloy had much higher wear resistance than steel, although it had lower hardness. The superior wear resistance of superelastic TiNi alloy was attributed to low $\mathrm{E} / \mathrm{H}$ and high elastic recovery ratio [3] [11]. Lin et al. [13] studied the effect of various applied loads on wear characteristics of TiNi shape memory alloy. It was found that normal load, sliding distance, and sliding speed had considerable influences on superelasticity of TiNi alloy. Their experimental results showed that during sliding wear tests, weight loss increased with increasing load according to Archard's law [14]. They suggested that under low loads, the material was superelastic while at high loads superelasticity diminished. Recent studies on 60NiTi have shown a unique combination of high hardness, low elastic modulus and superior elasticity making it a potential candidate for bearing and gear applications [7] [15] [16]. Static indentation load capacity tests on 60NiTi were conducted by DellaCorte et al. [15]. They found that 60NiTi surfaces could resist higher load levels before permanent deformation than conventional bearing steels, such as AISI 440C, AISI M-50, AISI 52100, and REX 20. They attributed this behavior to increase in contact area and reductions in peak and mean contact stresses.

Furthermore, in addition to dent resistance, loading rate is also of significant importance to applications where denting is expected. Substantial amount of work has been done towards understanding the effect of strain rate under tensile properties, i.e., uniaxial loading. Recent studies on strain rate dependency on superelasticity of TiNi under tensile loading conditions have shown that increasing strain rate leads to shortening of the stress plateau and increasing the austenite to martensite transition stress during the deformation process [17]-[21]. The rise in transition stress was related to heat accumulation in the deformation zone during uniaxial loading [17] [18] [21]-[23]. It has also been found that the transition stress increases with increasing strain rate whereas recoverable strain decreases with increasing strain rate [24]. On the other hand, only limited work has been done to understand the effect of loading rate on superelastic TiNi under indentation loading, i.e., under localized compressive loads. Several recent studies have shown a relationship between loading rate and superelasticity under indentation conditions [10] [25] [26]. It was found that increasing loading rate partially diminished the martensite transformation in superelastic TiNi alloy. In other words, under high loading rates, superelastic TiNi alloy behaves similar to conventional materials. It has been proposed that the drop in superelasticity under high loading rates may be due to retardation of stress-induced martensite transformation [10]. Much work is needed to fully understand the effect of loading rate on superelastic behavior of TiNi under indentation loading conditions. Hence, the objective of the present work is to develop an understanding of the dent and wear behavior of equiatomic TiNi and compare to a new generation of shape memory alloys, i.e., $60 \mathrm{NiTi}$.

\section{Materials and Methods}

In order to investigate the superelastic effect of TiNi and $60 \mathrm{NiTi}$ under indentation and wear conditions, indentation and reciprocating wear tests were performed using a multi-function nano-mechanical/tribometer system using Berkovich indenter and tungsten carbide (WC) ball, respectively. A flat plate, $458 \times 97 \times 1 \mathrm{~mm}$ of superelastic equiatomic TiNi alloy was obtained from Johnson Matthey Inc. and cut into squares of $15 \times 15 \times 1 \mathrm{~mm}$ 
and mounted in Bakelite. The TiNi sheets were oxide free and in a semi polished conditions. The chemical composition (weight \%) of the as-received superelastic TiNi alloy is given in Table 1. 60NiTi aged, annealed, and solution treated blocks having dimensions of $45 \times 45 \times 5 \mathrm{~mm}$ were prepared at National Aeronautics and Space Administration (NASA), Glenn Research Center, Cleveland, Ohio. The blocks of 60NiTi were cut into squares of $14 \times 14 \times 5 \mathrm{~mm}$ and mounted in Bakelite. The chemical compositions (weight \%) of the as-received $60 \mathrm{NiTi}$ under aged, annealed, and solution treated conditions are given in Table 2. Specimens were ground using 240, 320, 400 and 600 grit $\mathrm{SiC}$ abrasive paper followed by polishing using 1, 0.3 and $0.05 \mu \mathrm{m}$ aluminum oxide abrasive. Crystal structures and phases of equiatomic TiNi and aged, annealed, and solution treated 60NiTi were determined from x-ray diffraction patterns. X-ray diffraction (XRD) tests were carried out using a high speed Bruker D8 Advance XRD system with $\mathrm{CuK} \alpha$ radiation, tube current of $40 \mathrm{~mA}$, tube voltage of $40 \mathrm{kV}$ and radiation wavelength of $1.54 \AA$. The diffraction patterns were analyzed and compared to Powder Diffraction Files (PDF) database. The strongest peaks in all alloys are austenite peaks, which indicate that all alloys are austenitic at room temperature, hence, exhibiting superelastic behavior.

Indentation tests under varying loading rates and normal loads were conducted on TiNi and 60NiTi alloys using a nanoindentation system. The instrument uses a Berkovich diamond pyramid indenter with an angle of $65.3^{\circ}$ between the tip axis and the faces of the triangular pyramid. The displacement of indentation and the load are measured independently with resolutions of $0.03 \mathrm{~nm}$ and $0.1 \mu \mathrm{N}$. Hardness and elastic modulus of TiNi and 60NiTi were calculated from depth versus load curves using Oliver and Pharr's method [27]. The hardness is calculated according to,

$$
H=\frac{P}{24.5 h_{c}^{2}}
$$

where, $h_{c}$ is the contact depth of penetration and can be calculated from,

$$
h_{t}=h_{c}+\left[\frac{2(\pi-2)}{\pi}\right] \frac{P_{\max }}{\mathrm{d} P / \mathrm{d} h}
$$

where, $h_{t}$ is the total penetration depth, $P_{\max }$ is the maximum load and $\mathrm{d} P / \mathrm{d} h$ is the slope of the unloading curve. The elastic modulus of the system is given by,

$$
E^{*}=\frac{\mathrm{d} P}{\mathrm{~d} h} \frac{1}{2} \frac{\sqrt{\pi}}{\sqrt{A}}
$$

where,

$$
\frac{1}{E^{*}}=\frac{\left(1-v^{2}\right)}{E}+\frac{\left(1-v_{i}^{2}\right)}{E_{i}}
$$

where, $E$ and $v$ are the elastic modulus and Poisson's ratio for the specimen and $E_{i}$ and $v_{i}$ are the same parameters for the Berkovich indenter. In this study $E_{i}$ and $v_{i}$ were taken as $1141 \mathrm{GPa}$ and 0.07 , respectively. The loading rate and maximum load combinations were varied according to Table 3, i.e., a total of 63 tests for equiatomic $\mathrm{TiNi}$, and 189 tests for $60 \mathrm{NiTi}$ (aged, annealed and solution treated) were performed and each test was

Table 1. Chemical composition of equiatomic TiNi (wt $\%)$.

\begin{tabular}{cccccccc}
\hline Elements & $\mathrm{Ni}$ & $\mathrm{Ti}$ & $\mathrm{Fe}$ & $\mathrm{C}$ & $\mathrm{O}$ & $\mathrm{H}$ & Others \\
\hline $\mathrm{Wt} \%$ & 55.99 & 43.68 & 0.05 & $<0.05$ & 0.0216 & $<0.005$ & $<0.20$ \\
\hline
\end{tabular}

Table 2. Chemical composition of aged, annealed, and solution treated 60NiTi (wt $\%$ ).

\begin{tabular}{cccccccc}
\hline Elements & $\mathrm{Ni}$ & $\mathrm{Ti}$ & $\mathrm{Fe}$ & $\mathrm{Al}$ & $\mathrm{Cu}$ & $\mathrm{Ca}$ & Others \\
\hline Aged 60NiTi wt\% & 57.22 & 40.07 & 0.009 & 0.017 & 0.017 & 0.012 & $<0.10$ \\
Annealed 60NiTi wt\% & 60.23 & 41.79 & 0.007 & 0.019 & 0.014 & 0.009 & $<0.10$ \\
Solution treated 60NiTi wt\% & 61.52 & 43.16 & 0.009 & 0.021 & 0.011 & 0.015 & $<0.10$ \\
\hline
\end{tabular}


Table 3. Indentation test conditions.

Loading rate $(\mathrm{mN} / \mathrm{min})$

$300,600,1800,3000,4200,6000,18000$

$\operatorname{Max} \operatorname{load}(\mathrm{mN})$

$40,70,100,200,250,300,350,400,450$

repeated twice. Indentation tests showed excellent repeatability of not more than $5 \%$ variation. Loading and unloading (load versus depth) curves for different maximum loads were generated as a function of loading rate.

To investigate the tribological properties of equiatomic TiNi and $60 \mathrm{NiTi}$, reciprocating wear tests were conducted. Dry reciprocating wear tests were performed using a Universal Mirco-Tribometer (UMT) system. This test method involves a ball upper counter-face that slides against a flat lower specimen of polished TiNi and $60 \mathrm{NiTi}$ in a linear back and forth sliding motion, having a stroke length of $5.03 \mathrm{~mm}$. The load on the flat specimen is applied vertically downward with a motor driven carriage that uses a load sensor for feedback to maintain a constant load. The specimens were securely fastened inside the wear chamber. All the tests were conducted at room temperature with relative humidity of $40 \%-55 \%$. A $6.3 \mathrm{~mm}$ diameter tungsten carbide (WC) ball having a hardness of HRA 92 was used as a counter-face material. A WC ball was selected because it has much higher hardness than superelastic TiNi and 60NiTi. This minimizes wear of the counter-face and prevents shape change, which can lead to change in the contact geometry of the tribo-system, hence, change in mean pressure during testing. The tungsten carbide ball was mounted inside a ball holder which is attached directly to a suspension system and a load sensor that controls and records forces during the test. The instantaneous values of calibrated normal load (Fz) and tangential load (Fx) were measured and continuously recorded using a data acquisition system. The system automatically computes the variation of the coefficient of friction $(\mathrm{COF}=\mathrm{Fx} / \mathrm{Fz})$ with time. Wear tests for equiatomic superleastic TiNi and 60NiTi (aged, annealed and solution treated) were performed under normal loads of 20, 40, and $60 \mathrm{~N}$ with varying reciprocating frequencies from 5 to $20 \mathrm{~Hz}$ and time intervals between 30 to 180 minutes. The weight of specimens was measured before and after each test to determine individual weight-loss at 30 minutes intervals. The test method is based on ASTM standard G13305(2010) [28], i.e. standard test method for reciprocating sliding wear. After reciprocating wear tests, worn surfaces, tungsten carbide ball surface, and wear debris were examined using Hitachi S-4700 cold field Scanning electron microscopy. An Oxford $\AA$ X-Sight 7200 Energy Dispersive X-ray Spectroscopy (EDS) was used for chemical analysis of wear tracks.

\section{Results and Discussion}

Optical micrographs of equiatomic TiNi and aged, annealed, and solution treated 60NiTi are shown in Figures 1(a)-(d). Superelastic TiNi alloy (Figure 1(a)) shows regular equiaxed grains. The grain size appears to be uniform with an average size of $20 \mu \mathrm{m}$. On the other hand, aged, annealed, and solution treated 60NiTi show somewhat irregular and less uniform grain structure (Figures 1(b)-(d)). The average grain size appears to be 100 $\mu \mathrm{m}$.

60NiTi microstructure can be very complex depending on thermal treatment [1]. Depending upon aging temperature and time, metastable intermetallic phases (precipitates) such as $\mathrm{Ti}{ }_{2} \mathrm{Ni}, \mathrm{TiNi}_{3}, \mathrm{Ti}_{2} \mathrm{Ni}_{3}$ and $\mathrm{Ti}_{3} \mathrm{Ni}_{4}$ may form. $\mathrm{Ti}_{3} \mathrm{Ni}_{4}$ is the stable phase at lower aging temperature $\left(680^{\circ} \mathrm{C}\right)$ and shorter time which changes to $\mathrm{Ti}_{2} \mathrm{Ni}_{3}$ upon increasing aging temperature $\left(750^{\circ} \mathrm{C}\right)$ and extended time. $\mathrm{TiNi}_{3}$, on the other hand, appears at higher aging temperature $\left(800^{\circ} \mathrm{C}\right)$ and longer aging time. Whether the precipitates are observed or not by optical metallography would depend on their size and coherency.

To evaluate the effect of loading rate on the deformation characteristics of superelastic TiNi and 60NiTi, loading-unloading (load versus depth) curves were generated as a function of maximum load and loading rate. Representative force-displacement (penetration depth of indenter) curves showing loading-unloading generated under $3000 \mathrm{mN} / \mathrm{min}$ loading rate and different maximum loads (for equiatomic TiNi as representative curves) using Berkovich indenter are given in Figure 2. The curves in the figure reveal typical load versus displacement patterns, i.e., a rise in indentation depth with increasing normal load. The flat part of the curves at the max load and at the bottom part of the unloading curves is allowed to compensate for creep and thermal drift effects. All the curves generated using different maximum loads overlap, as expected. The curves show high recoverable deformation and relatively small permanent deformation upon unloading. An average of over $60 \%$ recovery is observed as a result of the elastic and superelastic behavior of the alloys. It is also evident that even the indentation tests performed under the lowest load of $40 \mathrm{mN}$ have shown residual plastic deformation, which is expected 


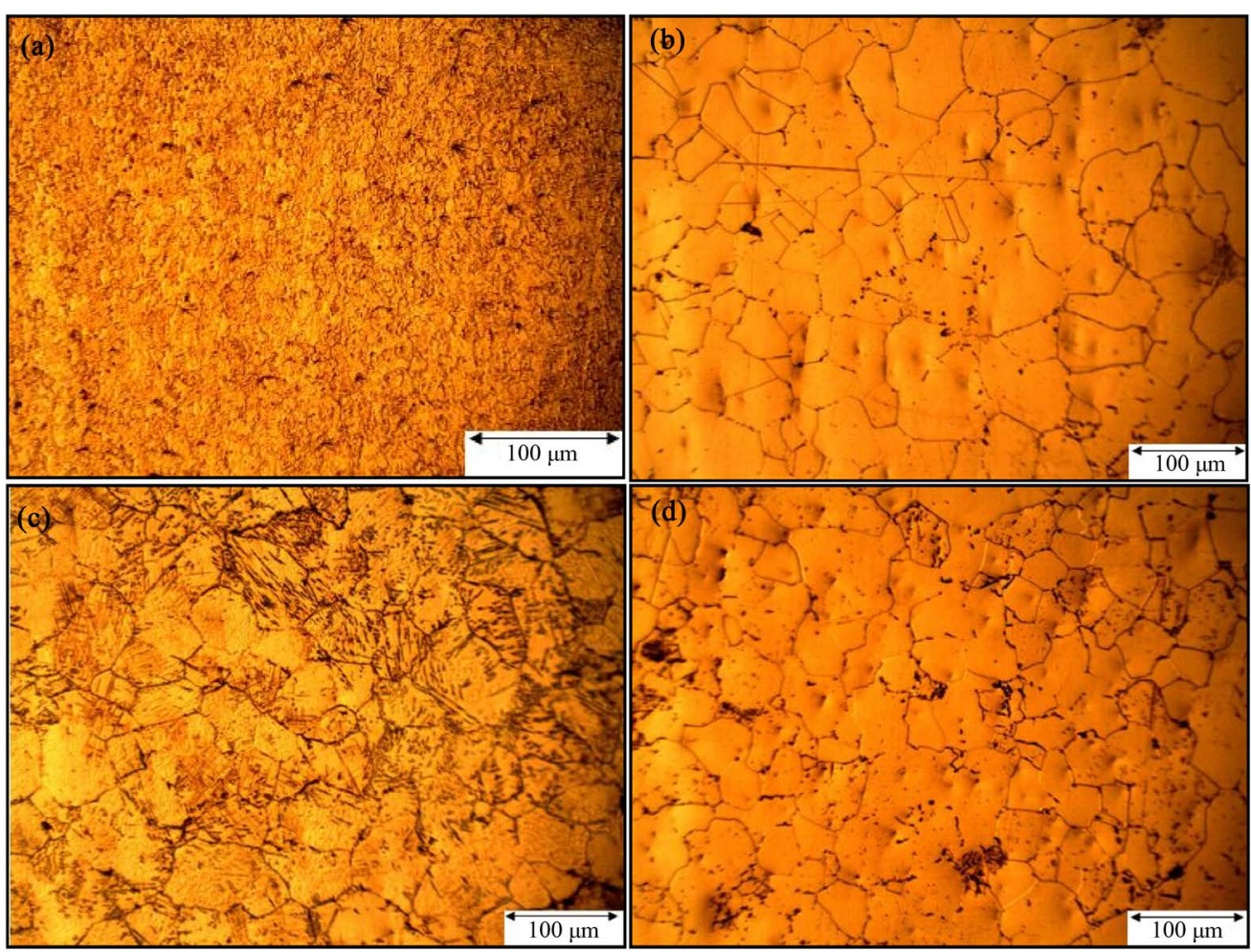

Figure 1. Optical micrographs: (a) equiatomic TiNi; (b) 60NiTi (aged); (c) 60NiTi (annealed); (d) $60 \mathrm{NiTi}$ (solution treated).

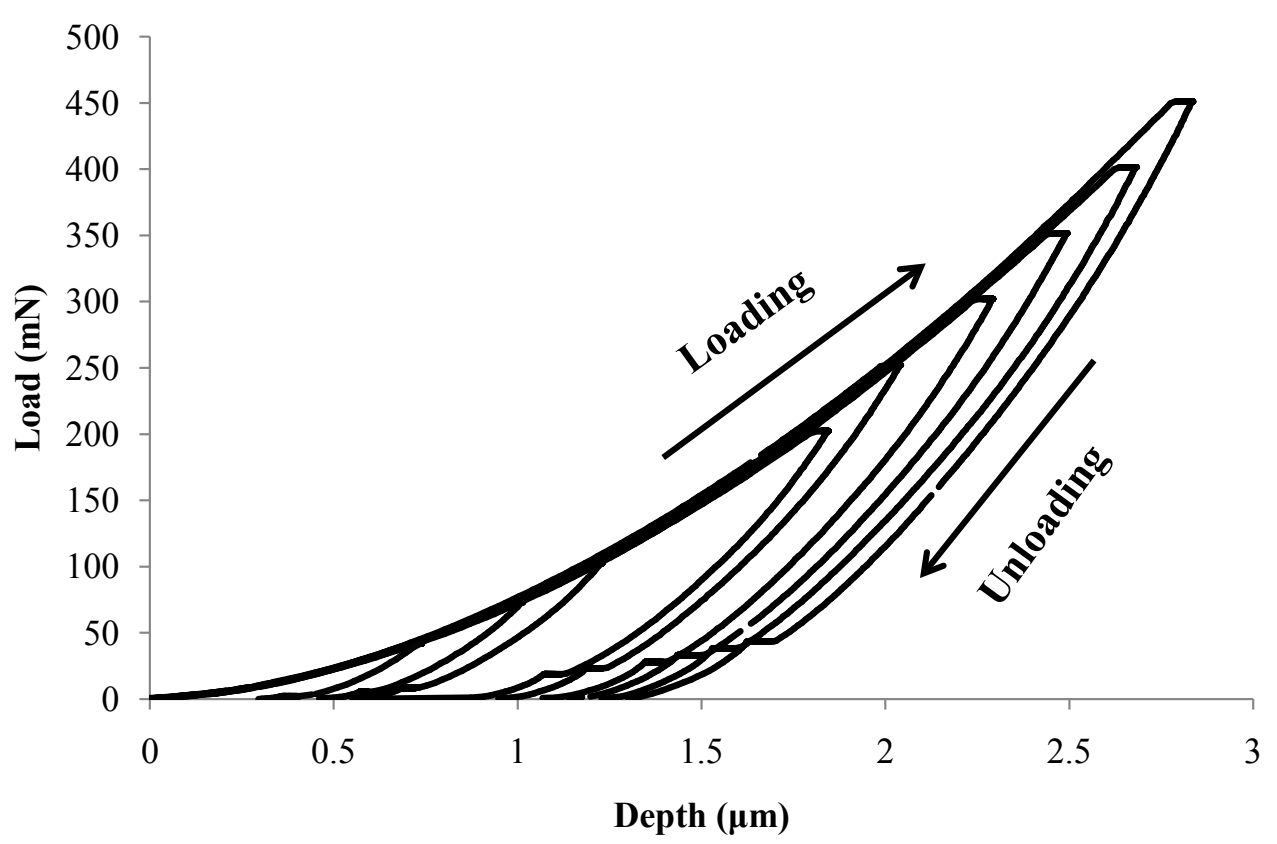

Figure 2. Indentation curves performed using $3000 \mathrm{mN} / \mathrm{min}$ loading rate with varying maximum loads for equiatomic TiNi.

for sharp indenter. The curves show the variation in hysteresis size as a function of maximum load, i.e., increases with maximum load.

Using data collected from indentation tests, maximum load versus maximum depth charts can be generated. 
Maximum load versus maximum depth values were plotted for aged 60NiTi as representative curve (Figure 3) to assess the effect of loading rate on the deformation characteristics of superelastic alloys. According to Figure 3 , the maximum depth of penetration seems to increase linearly with load for all loading rates. Data generated using different loading rates overlap with some scatter at high maximum loads. Similar trend was observed for all materials tested. This behavior indicates that the superelastic behavior of TiNi and 60NiTi, under the indentation conditions used in the present work is independent of loading rate. To further confirm this behavior, elastic recovery ratios were calculated for all loading-unloading curves. The elastic recovery ratio indicates the extent of elastic recovery during deformation and is calculated as the total area under the unloading curve over the total area under the loading curve. The elastic recovery ratio represents a better technique in assessing the effect of loading rate on the superelastic behavior, as this method takes the whole loading-unloading curve into consideration, as opposed to Figure 3 where only the maximum load and maximum depth were considered. The average elastic recovery ratio is plotted as a function of loading rate, as shown in Figure 4. The error bars indicate the scatter of the elastic recovery ratio calculated for various maximum loads at different loading rates. The average elastic recovery ratio for the equiatomic superelastic TiNi is 0.53 , which is over 7 times that of AISI 304 stainless steel (0.07) [11] although the hardness values of both materials are similar. The average elastic recovery ratios for $60 \mathrm{NiTi}$ (aged, annealed, and solution treated) are $0.53,0.46$ and 0.53 , respectively. It is believed that high elastic recovery ratio contributes to improved dent and wear resistance. That is, superelastic TiNi and 60NiTi have the capacity to accommodate high denting loads without permanently deforming. A closer examination of Figure 4 revels that the elastic recovery ratio is high at low loading rates and drops to steady-state, as loading rate increases. An approximate 5\%-10\% drop is observed in the elastic recovery ratio, which represents a mild drop in superelasticity as the loading rate is increased. This behavior might be attributed to retardation of the stress-induced martensitic transformation, i.e., the retardation of twin boundary mobility upon loading at high loading rates. Therefore, more plastic deformation takes place under the indenter tip, which leads to less recovery upon unloading. The mild dependency of superelasticity on loading rate (Figure 4) is not evident from Figure 2 and Figure 3, as the elastic recovery ratio represents a better measure of the amount of recoverable deformation.

Table 4 summarizes the mechanical properties of equiatomic TiNi, $60 \mathrm{NiTi}$ (aged, annealed and solution treated) and steel. The elastic recovery ratio given in Table 4 is the average value calculated for all the loading rates. It is interesting to note that the average elastic recovery for equiatomic TiNi and 60NiTi under different treatments are similar (except for annealed 60NiTi). The lower elastic recovery of the annealed 60NiTi is attributed to its higher $\mathrm{E} / \mathrm{H}$ ratio. Furthermore, it is evident from Table 4 that aged and solution treated $60 \mathrm{NiTi}$ exhibit

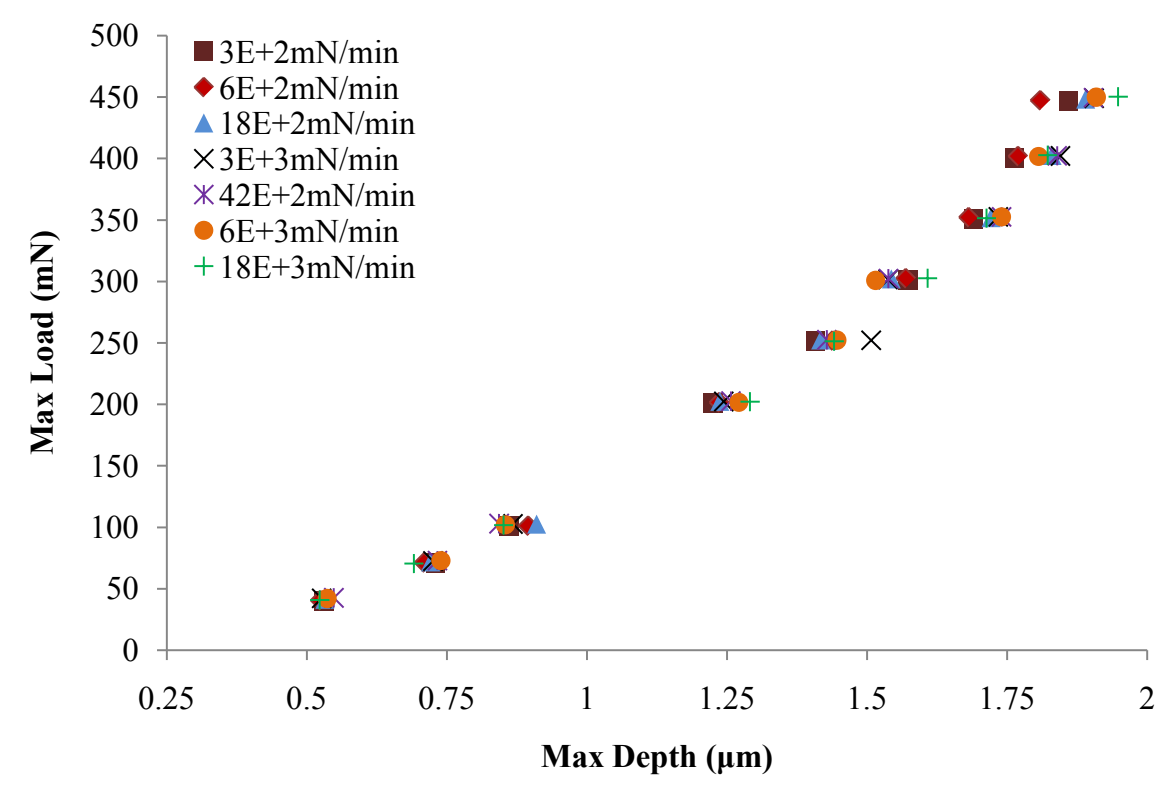

Figure 3. Max depth versus max load as a function of various loading rates for $60 \mathrm{NiTi}$ (aged). 


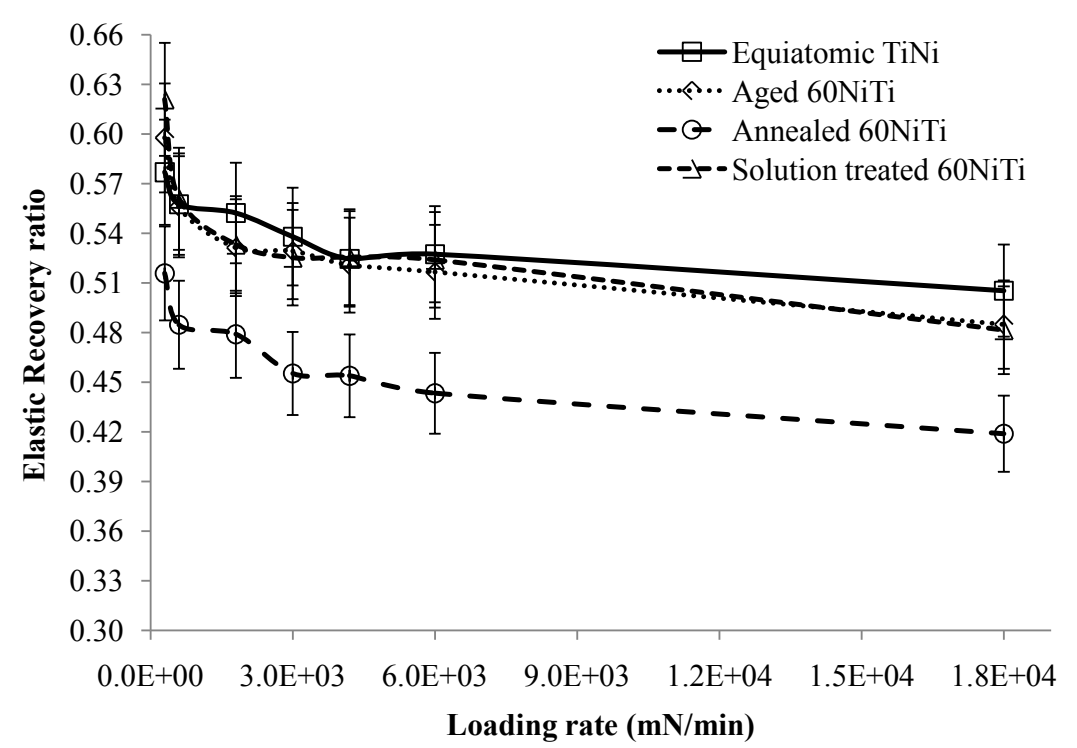

Figure 4. Elastic recovery ratio as a function of loading rate.

Table 4. Mechanical properties of equiatomic TiNi, 60NiTi (aged, annealed and solution treated) and AISI 304 stainless steel.

\begin{tabular}{ccccc}
\hline Properties & $\begin{array}{c}\text { Hardness }(\mathrm{H})(\mathrm{GPa}) \\
( \pm 0.2)\end{array}$ & $\begin{array}{c}\text { Young's modulus }(\mathrm{E})(\mathrm{GPa}) \\
( \pm 4)\end{array}$ & Elastic recovery ratio & $\mathrm{E} / \mathrm{H}$ \\
\hline Equiatomic TiNi & 3.2 & 50 & $0.53 \pm 0.02$ & 15 \\
60NiTi (aged) & 9.7 & 122 & $0.53 \pm 0.02$ & 12 \\
60NiTi (annealed) & 5.3 & 93 & $0.46 \pm 0.02$ & 17 \\
60NiTi & 9.3 & 113 & $0.53 \pm 0.02$ & 12 \\
(solution treated) & 2.7 & 229 & $0.070 \pm 0.003$ & 85 \\
AISI 304 stainless steel [11] & & & & \\
\hline
\end{tabular}

hardness values of about three times that of equiatomic $\mathrm{TiNi}$, while their $\mathrm{E} / \mathrm{H}$ values are lower than that of equiatomic TiNi. It is established in the open literature [3] [11] that superelastic materials exhibit low E/H ratio. Therefore, it can be concluded that aged and solution treated 60NiTi have enhanced superelastic behavior and superior hardness over equiatomic TiNi.

Reciprocating wear tests were performed under varying normal loads, frequencies and time intervals to study the wear behavior of equiatomic TiNi and aged, annealed, and solution treated 60NiTi. The cumulative weight loss versus sliding distance data was plotted and representative curves of equiatomic TiNi are shown in Figure $\mathbf{5}$. The typical variation in wear rates associated with these kinds of tests is less than 10\%. All the curves are characterized by two wear regimes. Initially the slope of the curve is high, i.e. high wear rate which is believed to be due to a "break-in" period as seen in Figure 5. The slope of the curve decreases to a lower steady state value, i.e. lower wear rate after a short sliding distance. In this break-in period, ploughing and polishing action occurs. Here, hard asperities of the WC ball plough through the softer TiNi surface and gradually remove TiNi asperities by polishing action accompanied by a drop in weight loss. Under the applied normal loads, as soon as the WC counterface ball comes in contact with the TiNi surface and sliding begins, it deforms the specimen surface and alters its roughness. The figure also shows that the weight loss increases with the increase in applied normal load for a constant reciprocating frequency of $10 \mathrm{~Hz}(5,15$ and $20 \mathrm{~Hz}$ also show the same trend). This behavior is attributed to the fact that higher applied normal loads promote higher levels of deformation leading to higher material removal rate. Similar behavior was observed for 60NiTi (aged, annealed and solution treated).

Typical variations of steady state wear rate as a function of frequency and normal load are given in Figure 6. Each data point in the diagram represents the steady-state wear rate for a given frequency and normal load. 


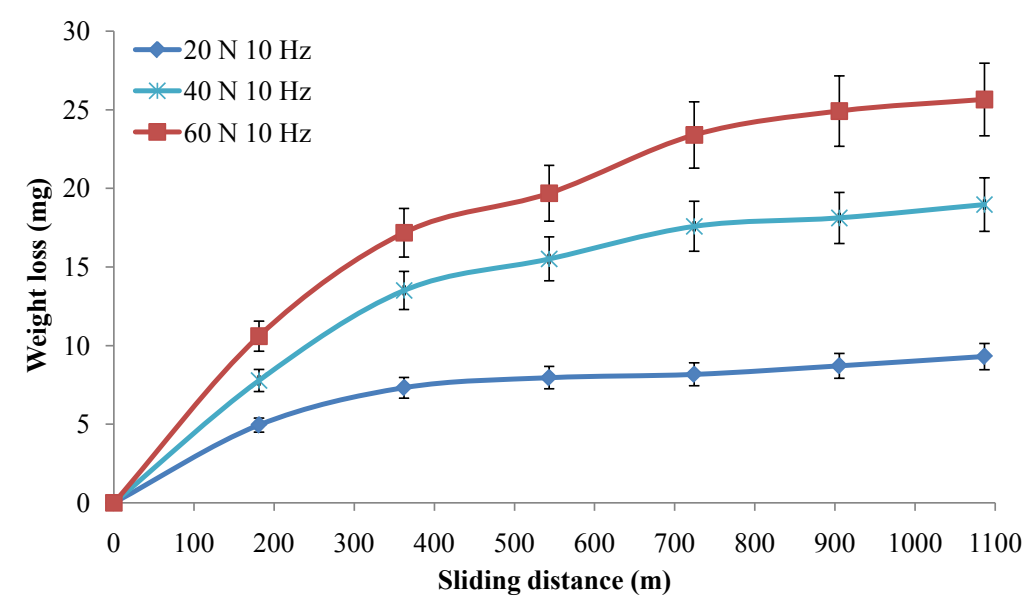

Figure 5. Cumulative weight loss versus sliding distance for different loads for equiatomic TiNi.

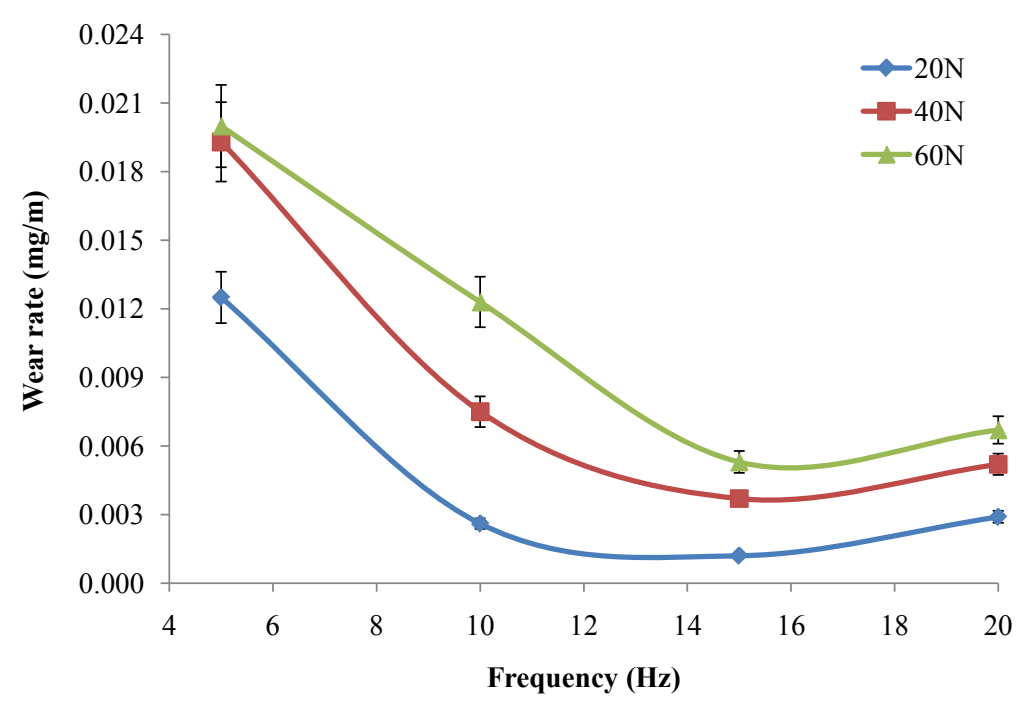

Figure 6. Steady state wear rate as a function of frequency for equiatomic TiNi.

These data points are calculated from the corresponding slope of the steady state region (see Figure 5). Normal load and frequency show significant influence on wear resistance as seen in Figure 5 and Figure 6 . The wear rate in Figure 6 is controlled by two effects occurring simultaneously. The first effect is due to softening of the superelastic alloys at high frequency as a result of heating and ultimately leading to higher wear. The second effect is due to rise in the austenite-to-martensite transition stress with temperature [29], which leads to increased wear resistance. The above discussed effects determine the observed wear rate. A drop in wear rate is clearly seen with increasing frequency up to $15 \mathrm{~Hz}$ followed by a mild rise to $20 \mathrm{~Hz}$. In the frequency range 5 to $15 \mathrm{~Hz}$, hardening effect due to rise in austenite-to-martensite transition stress as a result of increased temperature is dominant. However, when the frequency is raised over $15 \mathrm{~Hz}$, the softening effect due to heating seems to be more dominant. Furthermore, the steady-state wear rate increases with increasing normal load.

During the reciprocating wear tests, the instantaneous values of calibrated normal force (Fz) and tangential force $(\mathrm{Fx})$ were measured and the coefficient of friction (COF) was calculated. The COF is plotted as a function of sliding distance for different loads. Representative curves of equiatomic TiNi are shown in Figure 7. The basic shape of the friction curve remains similar under all testing conditions and materials. COF versus sliding distance curves is characterized by two friction regimes. Initially, the coefficient of friction increases until it reaches a maximum steady-state value. The COF becomes independent of sliding distance at steady-state region.

Table 5 gives the steady-state coefficient of friction as a function of frequency for equiatomic TiNi and 


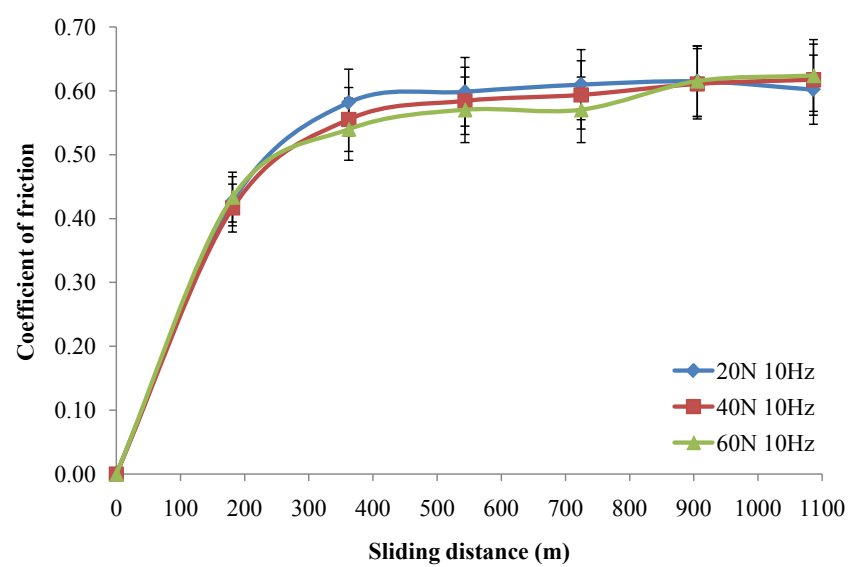

Figure 7. Coefficient of friction versus sliding distance for different loads for equiatomic TiNi.

Table 5. Steady-state COF of equiatomic TiNi and 60NiTi (aged, annealed and solution treated).

\begin{tabular}{ccccc}
\hline Frequency $(\mathrm{Hz})$ & Equiatomic TiNi & 60NiTi (aged) & 60NiTi (annealed) & 60NiTi (solution treated) \\
\hline 5 & 0.60 & 0.59 & 0.58 & 0.54 \\
10 & 0.58 & 0.56 & 0.54 & 0.53 \\
15 & 0.51 & 0.52 & 0.52 & 0.49 \\
20 & 0.45 & 0.46 & 0.46 & 0.43 \\
\hline
\end{tabular}

60NiTi (aged, annealed and solution treated). According to Table 5, the COF drops as the reciprocating frequency rises for all the employed normal loads. It is well established that the COF is controlled by both surface and bulk properties in accordance with the general rule [30]:

$$
\mathrm{COF}=\tau_{s} / H_{b}
$$

where, $\tau_{s}$ is surface shear strength and $H_{b}$ is the bulk hardness. It can be argued that the drop in coefficient of friction with frequency is dominated by surface softening due to heating, which gives rise to a corresponding drop in surface shear strength. Hence, the COF seems to vary only with heating effects. On the other hand, it is found that there is no significant change in the COF, with normal load and each COF value given in Table 5 is an average of the COF values measured using 20, 40 and $60 \mathrm{~N}$ loads. As seen in Table 5, the values of the steady-state $\mathrm{COF}$ for equiatomic TiNi and 60NiTi (aged, annealed and solution treated) range between 0.43 and 0.60. Furthermore, the average coefficient of friction over the frequency range $(5-20 \mathrm{~Hz})$ are $0.54,0.53,0.53$ and 0.50 , respectively for equiatomic TiNi, $60 \mathrm{NiTi}$ (aged), $60 \mathrm{NiTi}$ (annealed), and $60 \mathrm{NiTi}$ (solution treated).

Wear data for equiatomic TiNi and 60NiTi (aged, annealed and solution treated) can be described by Archards-type law for sliding wear and the specific wear rate can be determined using Archard's equation, $V=k F s$, where, $V$ is wear volume, $k$ is specific wear rate, $F$ is normal load, and $s$ is sliding distance. Wear volume is calculated by dividing the measured weight loss (for $10 \mathrm{~Hz}$ frequency) by the density of TiNi $(6.45 \mathrm{~g} / \mathrm{cc}$ ) and $60 \mathrm{NiTi}(6.7 \mathrm{~g} / \mathrm{cc})$. Table 6 summarizes the specific wear rates of equiatomic TiNi and $60 \mathrm{NiTi}$ (aged, annealed and solution treated). Examination of Table 6 shows that aged and solution treated $60 \mathrm{NiTi}$ exhibit about $40 \%$ improvement in wear resistance over equiatomic TiNi. This enhancement in wear resistance is due to the higher hardness of aged and solution treated 60NiTi compared to equiatomic TiNi (see Table 4). The specific wear rates for TiNi and 60NiTi reported in Table 6 are lower than those reported for many wear resistant materials [31] [32]. Equiatomic superelastic TiNi and 60NiTi show lower specific wear rate compared to medium carbon steel $\left(10^{-4} \mathrm{~mm}^{3} / \mathrm{Nm}\right.$ ), stainless steel $\left(10^{-4} \mathrm{~mm}^{3} / \mathrm{Nm}\right.$ ), high carbon and tool steels (range $10^{-4} \mathrm{~mm}^{3} / \mathrm{Nm}$ to $10^{-5}$ $\mathrm{mm}^{3} / \mathrm{Nm}$ ) [31] and, hardened AISI 52100 bearing steel (range $9.6 \times 10^{-5} \mathrm{~mm}^{3} / \mathrm{Nm}$ to $1.6 \times 10^{-4} \mathrm{~mm}^{3} / \mathrm{Nm}$ ) [32] Here, hardened AISI 52100 bearing steel data was generated using ball-on-disc test. However, in the absence of data generated using reciprocating sliding wear, it is reasonable to state, based on the available data, that equiatomic TiNi and $60 \mathrm{NiTi}$ exhibit superior wear resistance. 
Table 6. Specific wear rates of equiatomic TiNi and 60NiTi (aged, annealed and solution treated).

\begin{tabular}{cc} 
Material & Specific wear rate $\left(\mathrm{mm}^{3} / \mathrm{Nm}\right)$ \\
\hline Equiatomic TiNi & $10.86 \times 10^{-5}$ \\
Aged 60NiTi & $7.02 \times 10^{-5}$ \\
Annealed 60NiTi & $9.73 \times 10^{-5}$ \\
Solution treated 60NiTi & $6.66 \times 10^{-5}$ \\
\hline
\end{tabular}

Morphological analysis of equiatomic TiNi and 60NiTi worn surfaces and the tungsten carbide (WC) ball counter-face were investigated using scanning electron microscopy and electron dispersive spectroscopy to understand the operative wear mechanisms. Examination of the WC ball counter-face surface reveals clear evidence of adhesive wear. Adhesive wear occurs as a result of the formation of asperity junctions (cold weld) between the two surfaces in contact. This is followed by the shearing of the junction leaving material from one surface attached to the other surface. SEM micrograph and EDS results confirm the presence of TiNi layer on the WC ball surface as shown in Figure 8. Figure 8 insert shows Ti and Ni peaks appearing together with W, C, and Co.

SEM examination of aged 60NiTi wear tracks subjected to $60 \mathrm{~N}$ and $20 \mathrm{~Hz}$ revels evidence of plastic flow of material in the sliding direction, deep grooves oriented along the sliding direction and oxide formation on the wear tracks as shown in Figure 9. The presence of grooves and ridges on the wear track are evidence of abrasive wear. The grooves are a result of ploughing action by the counter-face and/or loose wear debris as third party abrasion. Abrasive wear seems to be more dominant in equiatomic TiNi, aged 60NiTi and solution treated 60NiTi. Besides adhesive and abrasive wear, evidence of delamination wear can also be observed from Figure 10. In delamination, wear takes place by heavy plastic deformation of the surface layers, nucleation of subsurface cracks where shear stress is maximum, and propagation of these cracks parallel to the surface. A surface pit forms as a result of delamination, as can be seen in Figure 9. Figure 10 clearly show the formation of plate-like wear particle by delamination. It is believed that delamination in superelastic alloys is promoted by the mismatch in the elastic properties across the sample cross section, which in turn, leads to accelerated delamination. During sliding wear, the top surface of the superelastic alloys experience heavy plastic deformation and loose their superelastic property, which causes martensite to stabilize; while, subsurface layers still behave in a superelastic manner. Hence, this mismatch in mechanical properties causes nucleation of cracks at the interface and propagation of these cracks parallel to the surface. Delamination wear seems to be more dominant in annealed 60NiTi. A high magnification image of the wear track in Figure 11 shows extensive Hertzian-type micro-cracks. Micro-cracks are developed due to surface tensile stress and extend perpendicular to the sliding direction. It was found that micro-cracks are more prominent at high load and high frequency.

\section{Conclusions}

In the present work, dent and wear behaviors of equiatomic superelastic TiNi and 60NiTi are investigated and the following conclusions are reached:

1) Within the indentation condition employed in this study, the indentation behavior and dent resistance of TiNi and $60 \mathrm{NiTi}$ are not significantly affected by loading rate. Only a mild drop of about $5 \%-10 \%$ in superelasticity is observed as the loading rate is increased. This drop may be due to retardation of martensitic transformation upon loading at high loading rates;

2) The superior wear and dent resistance of superelastic equiatomic TiNi and $60 \mathrm{NiTi}$ is attributed to low $\mathrm{E} / \mathrm{H}$ and high elastic recovery ratio. The E/H value of TiNi is 15 while that of AISI 304 steel is 85 . The average elastic recovery ratio for superelastic TiNi obtained from nanoindentation tests is over 7 times than that of AISI 304 stainless steel, although both have similar hardness;

3) Aged and solution treated new generation 60NiTi exhibits slightly enhanced superelasticity compared to equiatomic TiNi (i.e., lower E/H), yet they show about 3 times the hardness, slightly lower COF and about $40 \%$ improvement in wear resistance;

4) Adhesive, abrasive and delamination wear mechanisms have been identified. Adhesive wear and abrasive wear are more dominant in equiatomic $\mathrm{TiNi}$, aged $60 \mathrm{NiTi}$ and solution treated $60 \mathrm{NiTi}$, while adhesive wear and delamination wear are more dominant in annealed 60NiTi. 


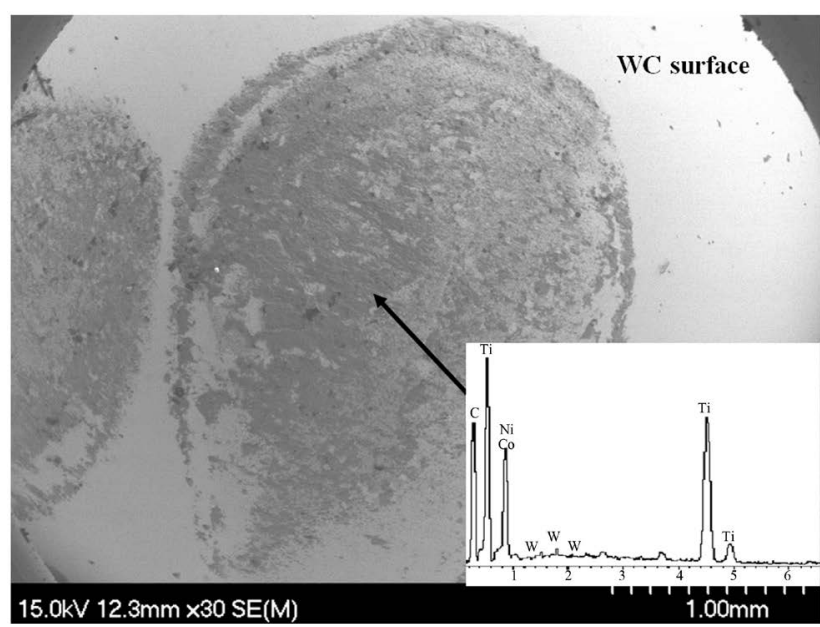

Figure 8. SEM micrograph of WC ball showing TiNi transfer layer.

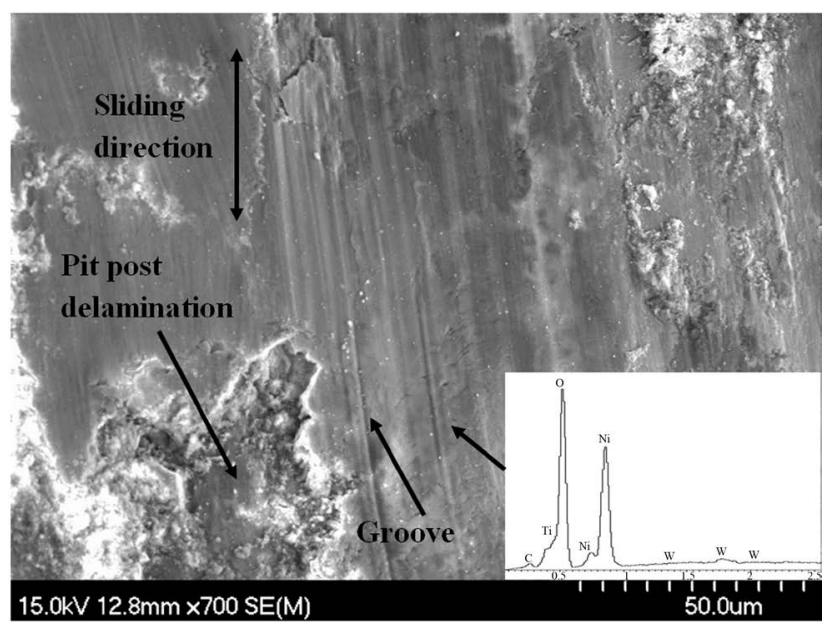

Figure 9. SEM micrograph of aged $60 \mathrm{NiTi}$ wear track subjected to $60 \mathrm{~N}$ load and $20 \mathrm{~Hz}$ frequency at the end of the wear test.

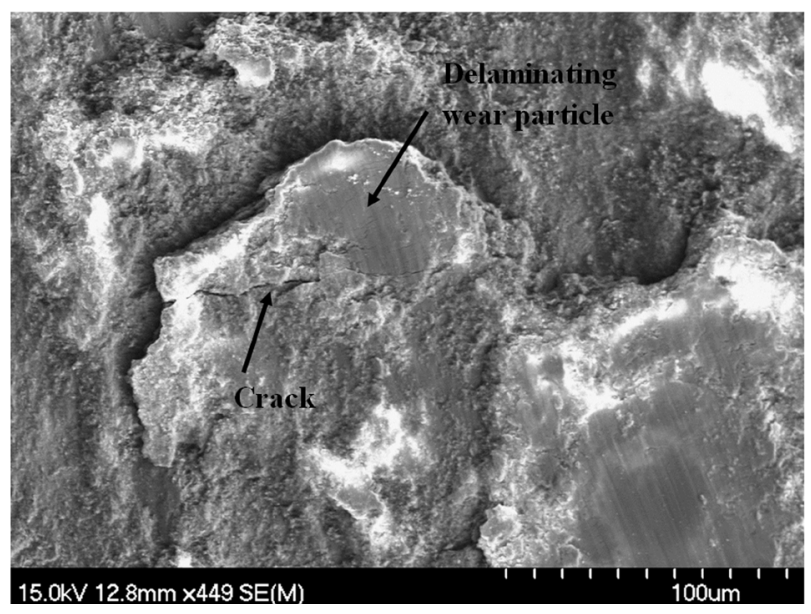

Figure 10. SEM image of aged 60NiTi wear track subjected to $60 \mathrm{~N}$ load and $20 \mathrm{~Hz}$ frequency at the end of the wear track with delaminating wear particle. 


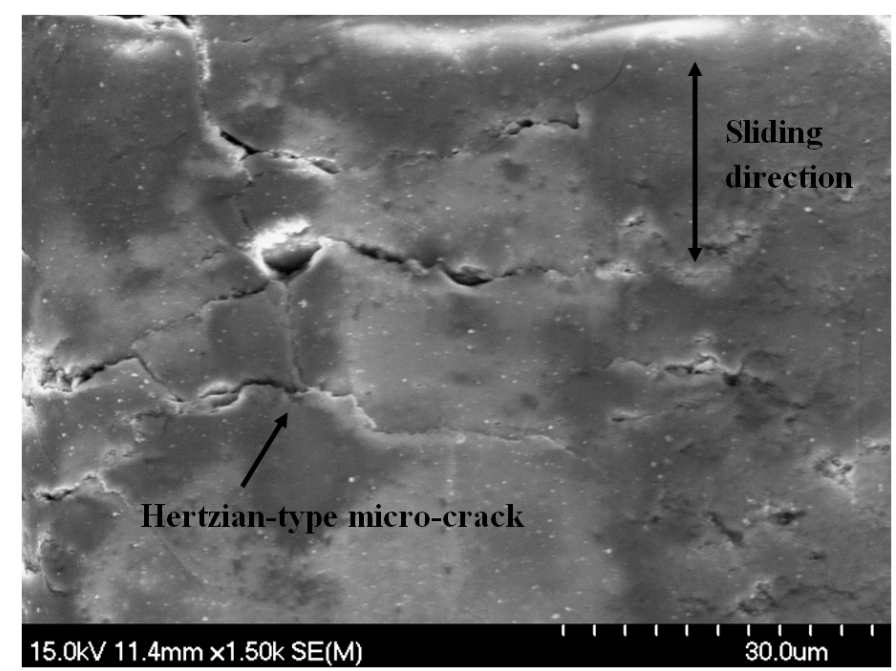

Figure 11. SEM images of annealed 60NiTi wear track subjected to $60 \mathrm{~N}$ load and $20 \mathrm{~Hz}$ frequency at the end of the wear test.

\section{Acknowledgements}

The authors would like to thank the Natural Sciences and Engineering Research Council of Canada (NSERC) for financial support, and Dr. Malcolm K. Stanford and Dr. Christopher DellaCorte, National Aeronautics and Space Administration (NASA), Glenn Research Center, Cleveland, Ohio for the preparation of the 60NiTi.

\section{References}

[1] Otsuka, K. and Ren, X. (2005) Physical Metallurgy of Ti-Ni Based Shape Memory Alloys. Progress in Materials Science, 50, 511-678. http://dx.doi.org/10.1016/j.pmatsci.2004.10.001

[2] Lagoudas, D., Ed. (2008) Shape Memory Alloys Modeling and Engineering Applications. Springer, New York.

[3] Neupane, R. and Farhat, Z. (2013) Wear and Dent Resistance of Superelastic TiNi Alloy. Wear, 301, 682-687. http://dx.doi.org/10.1016/j.wear.2012.11.017

[4] Li, D. (2000) Development of Novel Wear-Resistant Materials: TiNi-Based Pseudoelastic Tribomaterials. Materials \& Design, 21, 551-555. http://dx.doi.org/10.1016/S0261-3069(00)00015-7

[5] Li, D. (1998) A New Type of Wear-Resistant Material: Pseudo-Elastic TiNi Alloy. Wear, 221, 116-123. http://dx.doi.org/10.1016/S0043-1648(98)00269-5

[6] Neupane, R. and Farhat, Z. (2014) Wear Mechanisms of Nitinol under Reciprocating Sliding Contact. Wear, 315, 2530. http://dx.doi.org/10.1016/j.wear.2014.02.018

[7] DellaCorte, C., Pepper, S., Noebe, R., Hull, D. and Glennon G. (2009) Intermetallic Nickel-Titanium Alloys for OilLubricated Bearing Applications. Power Transmission Engineering, 8, 26-35.

[8] Julien, G. (2005) Nitinol Ball Bearing Element and Process for Making. US Patent No. 6886986 B1.

[9] Julien, G. (2006) Shape Memory Parts of 60 Nitinol. US Patent No. 7005018 B2.

[10] Farhat, Z., Jarjoura, G., and Shahirnia, M. (2013) Dent Resistance and Effect of Indentation Loading Rate on Superelastic TiNi Alloy. Metallurgical and Materials Transactions A, 44, 3544-3551. http://dx.doi.org/10.1007/s11661-013-1727-6

[11] Farhat, Z. and Zhang, C. (2010) The Role of Reversible Martensite Transformation in the Wear Process of TiNi Shape Memory Alloy. Tribology Transactions, 53, 917-926. http://dx.doi.org/10.1080/10402004.2010.510620

[12] Li, D. and Liu, R. (1999) The Mechanism Responsible for High Wear Resistance of Pseudo-Elastic TiNi Alloy-A Novel Tribo-Material. Wear, 225-229, 777-783. http://dx.doi.org/10.1016/s0043-1648(98)00388-3

[13] Lin, H., He, J., Chen, K., Liao, H. and Lin, K. (1997) Wear Characteristics of TiNi Shape Memory Alloys. Metallurgical and Materials Transactions A, 28, 1871-1877. http://dx.doi.org/10.1007/s11661-997-0117-3

[14] Archard, J.F. (1953) Contact and Rubbing of Flat Surfaces. Journal of Applied Physics, 24, 981-988. http://dx.doi.org/10.1063/1.1721448 
[15] DellaCorte, C., Moore III, L.E. and Clifton, J.S. (2013) The Effect of Pre-Stressing on the Static Indentation Load Capacity of the Superelastic 60NiTi. NASA TM 2013-216479.

[16] Canter, N. (2014) Corrosion-Proof Nickel Titanium Bearings. Tribology \& Lubrication Technology, 70, 10-11.

[17] Wang, Z., Lei, H., Zhou, B., Wang, Y. and Zhang, C. (2011) Influence of Strain Rate on Mechanical Properties of Shape Memory Alloy. Key Engineering Materials, 467-469, 585-588. http://dx.doi.org/10.4028/www.scientific.net/KEM.467-469.585

[18] Liu, Y., Li, Y. and Ramesh, K.T. (2002) Rate Dependence of Deformation Mechanisms in a Shape Memory Alloy. Philosophical Magazine A, 82, 2461-2473. http://dx.doi.org/10.1080/01418610208240046

[19] Vitiello, A., Giorleo, G. and Morace, R.E. (2005) Analysis of Thermomechanical Behaviour of Nitinol Wires with High Strain Rates. Smart Materials and Structures, 14, 215. http://dx.doi.org/10.1088/0964-1726/14/1/021

[20] Lim, T.J. and McDowell, D.L. (1999) Mechanical Behavior of an Ni-Ti Shape Memory Alloy under Axial-Torsional Proportional and Nonproportional Loading. Journal of Engineering Materials and Technology, 121, 9-18. http://dx.doi.org/10.1115/1.2816007

[21] Lin, P., Tobushi, H., Tanaka, K., Hattori, T. and Makita, M. (1994) Pseudoelastic Behaviour of TiNi Shape Memory Alloy Subjected to Strain Variations. Journal of Intelligent Material Systems and Structures, 5, 694-701. http://dx.doi.org/10.1177/1045389X9400500514

[22] Tobushi, H., Yoshirou, S., Takashi, H. and Kikuaki, T. (1998) Influence of Strain Rate on Superelastic Properties of TiNi Shape Memory Alloy. Mechanics of Materials, 30, 141-150. http://dx.doi.org/10.1016/S0167-6636(98)00041-6

[23] Dayananda, G.N. and Rao, M.S. (2008) Effect of Strain Rate on Properties of Superelastic NiTi Thin Wires. Materials Science and Engineering: A, 486, 96-103. http://dx.doi.org/10.1016/j.msea.2007.09.006

[24] Saletti, D., Pattofatto, S. and Zhao, H. (2010) Evolution of the Martensitic Transformation in Shape Memory Alloys under High Strain Rates. EPJ Web of Conferences, 14th International Conference on Experimental Mechanics, 6, Article No. 29008. http://dx.doi.org/10.1051/epjconf/20100629008

[25] Shahirnia, M., Farhat, Z. and Jarjoura, G. (2011) Effects of Temperature and Loading Rate on the Deformation Characteristics of Superelastic TiNi Shape Memory Alloys under Localized Compressive Loads. Materials Science and Engineering: A, 530, 628-632. http://dx.doi.org/10.1016/j.msea.2011.10.034

[26] Amini, A., He, Y. and Sun, Q. (2011) Loading rate Dependency of Maximum Nanoindentation Depth in Nano-Grained NiTi Shape Memory Alloy. Materials Letters, 65, 464-466. http://dx.doi.org/10.1016/j.matlet.2010.10.026

[27] Oliver, W. and Pharr, G. (1992) An Improved Technique for Determining Hardness and Elastic Modulus Using Load and Displacement Sensing Indentation Experiments. Journal of Materials Research, 7, 1564-1583. http://dx.doi.org/10.1557/JMR.1992.1564

[28] ASTM Standard G133-05 (2010) Standard Test Method for Linearly Reciprocating Ball-on-Flat Sliding Wear. ASTM International, West Conshohocken. http://dx.doi.org/10.1520/G0133-05R10

[29] Otsuka, K. and Shimizu, K. (1986) Pseudoelasticity and Shape Memory Effects in Alloys. International Metals Reviews, 31, 93-114. http://dx.doi.org/10.1179/imtr.1986.31.1.93

[30] Larsen-Basse, J. (1992) Introduction to Friction. In: Blau, P., Ed., ASM Handbook, Vol. 18: Friction, Lubrication, and Wear Technology, ASM International, Materials Park, 27-38.

[31] Ashby, M.F. (2005) Materials Selection in Mechanical Design. Butterworth-Heinemann, Amsterdam.

[32] Sen, S. and Sen, U. (2009) The Effect of Boronizing and Boro-Chromizing on Tribological Performance of AISI 52100 Bearing Steels. Industrial Lubrication and Tribology, 61, 146-153. http://dx.doi.org/10.1108/00368790910953668 